$0.607-0.816)$, being slightly lower. A proximal diameter $\geq 7.5 \mathrm{~mm}$ provides a specificity of $87.2 \%(95 \% \mathrm{Cl}$ : 76.7-96.7) and a sensitivity of $65.3 \%(95 \% \mathrm{Cl}: 51.9-$ 78.6) for esophageal dysmotility, enabling correct classification of $75 \%$ of the patients. A distal diameter $\geq 12.9 \mathrm{~mm}$ provides a specificity of $76.6 \%(95 \% \mathrm{Cl}$ : $64.5-88.7)$ and a sensitivity of $71.2 \%(95 \% \mathrm{Cl}: 58.8-83.5)$, correctly classifying $73 \%$ of the patients.

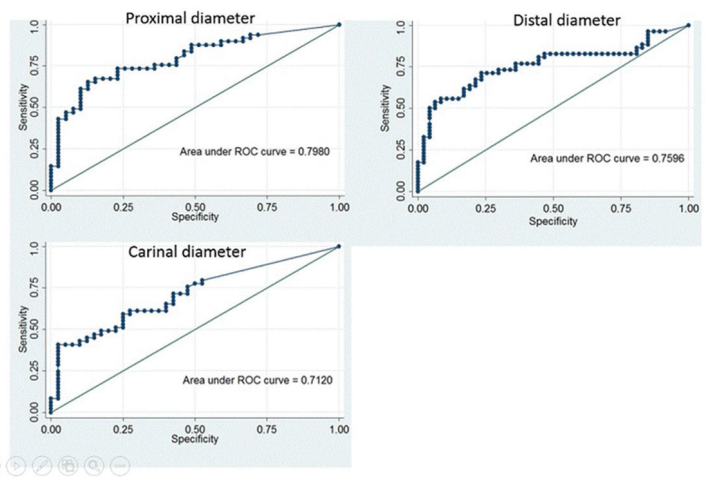

Abstract THU0391 - Figure 1. ROC curves of the diameters for esophageal dysmotility detected by manometry.

Conclusions: CT, a less invasive technique than manometry, can be an acceptable diagnostic tool for esophageal dysmotility in SSc, when the maximum proximal or distal esophageal diameter are $\geq 7.5 \mathrm{~mm}$ and $12.9 \mathrm{~mm}$, respectively. CT done in the daily clinical practice could be exploited when manometry is not preferred in selected patients with SSc. More studies need to be carried out to confirm this results.

Disclosure of Interest: None declared

DOI: 10.1136/annrheumdis-2018-eular.4782

\section{THU0392 SYSTEMIC SCLEROSIS AND PRIMARY BILIARY CHOLANGITIS: AN OVERLAP SYNDROME? PRELIMINARY DATA FROM A MULTICENTRE EUSTAR STUDY}

${ }^{1}$ G. Lepri, P. Airò ${ }^{2}$, O. Distler ${ }^{3}$, K. Andréasson ${ }^{4}$, Y. Braun-Moscovici ${ }^{5}$, E. DeLanghe $^{6}$, C. Bruni ${ }^{1}$, M. Matucci-Cerinic ${ }^{1}, Y$. Allanore ${ }^{7}$, on behalf of EUSTAR coauthors. ${ }^{1}$ Rheumatology, University of Florence, Florence; ${ }^{2}$ Rheumatology and Clinical Immunology, Spedali Civili, Brescia, Brescia, Italy; ${ }^{3}$ Rheumatology, University Hospital Zurich, Zurich, Switzerland; ${ }^{4}$ Clinical Sciences, Lund University, Lund, Sweden; ${ }^{5}$ Rheumatology Department, Rambam Health Care Campus, Rappaport Faculty of Medicine, Technion, Haifa, Haifa, Israel; ${ }^{6}$ Rheumatology, University Hospitals Leuven, Leuven, Belgium; ${ }^{7}$ Rheumatology A, Paris Descartes University, Paris, France

Background: The association between systemic sclerosis (SSc) and primary biliary cholangitis (PBC) is well known. However, classifications criteria of the 2 diseases have been recently revised and may change the relationships. Furthermore, the specific outcomes with regards to organ involvement and also of liver aspects have been only scarcely investigated.

Objectives: To describe clinical characteristics of SSc-PBC patients compared to SSc using a large series

Methods: A multicentre EUSTAR study collection data of SSc patients with known PBC or with PBC-specific antibodies (abs) and of SSc controls matched for disease duration and cutaneous subset. Data were recorded at baseline and at the last available visit.

Results: 229 patients were enrolled ( 85 SSc-PBC and 144 SSc). The mean age of the population at the SSc diagnosis was of $53 \pm 12.8$. Baseline characteristics. The limited cutaneous subset was the most common. Anticentromere abs (ACA) were present in $82.9 \%$ of SSc-PBC patients (vs $68.5 \%$ in SSc, $p$-value $=0.01$ ) while anti-topoisomerase I abs were less frequently (1.2\% vs $9.7 \%)$, $p$ value $=0.02$. Out of $85 \mathrm{SSc}-\mathrm{PBC}$ patients, antimitochondrial abs (AMA) were present in $80 \%$, only $9.4 \%$ presented anti-gp 210 abs and $7.1 \%$ anti-sp 100 abs. The two populations did not differ for fibrosis at HRCT, lung function tests, the value of creatinine and for pulmonary arterial hypertension. A trend towards statistical significance was found in the prevalence of digital ulcers (DUs) as patients that have never suffered from past or current DUs were greater in the SSc-PBC group $(78.6 \%$ vs $66 \%$, $p$-value $=0.051)$. Regarding other autoimmune associated diseases, a greater prevalence of Hashimoto thyroiditis was found in SSc-PBC ( $p$ value $=0.03$ ). At baseline, transaminase, alkaline phosphatase and $\gamma \mathrm{GT}$ levels were all higher in PBC-SSc $(p$-value $<0.001)$ (see Fig 1). Outcomes of organ involvements. The mean follow-up was of $10.5 \pm 6.8$ years. During the follow-up the percentage of patients presenting ILD (defined as new appearance of fibrosis at control HRCT scan) was greater in SSc vs SSc-PBC $(12.9 \%$ vs $2.8 \%, p$ value $=0.02$ ) and PAH percentage of new cases was of $9.9 \%$ in SSc while it was not present in SSc-PBC ( $p$-value $=0.003)$.

\begin{tabular}{|c|c|c|c|}
\hline & SSC-PBC population & Ssc controls & p-volve \\
\hline $\begin{array}{l}\text { Cutaneous subset } \\
\text { Limited cutaneous subset } \\
\text { Diftuse cutaneous subset }\end{array}$ & $\begin{array}{l}77(90.656) \\
2(2.456) \\
6671.164\end{array}$ & $\begin{array}{l}132(91.786) \\
5(3.56) \\
7(1.596 \%)\end{array}$ & 0.75 \\
\hline CTffibrosis & $15(17.6 \% 6)$ & $28(19.445)$ & 0.69 \\
\hline FVC (forced vital capacity) [mean $\$$ SO] & $104.3 \div 21.5$ & $103.2 \div 17.1$ & 0.72 \\
\hline DLCO (dilfusing capaciry for carbon monoxide) [mean $\leqslant$ SO] & $78.3 \div 18.3$ & $76.5 \pm 17.5$ & 0.50 \\
\hline Portal hypertension & $4(4.796)$ & & \\
\hline Arthyethmis & $4(4.786)$ & $4(2.8 \% 6)$ & 0.55 \\
\hline Conduction block & $7(8256)$ & $7(4.966)$ & 0.39 \\
\hline PAH & $5(5.968)$ & $2(1.456)$ & 0.10 \\
\hline Never OUs & $66(77.6 \% 6)$ & $95(66 \%)$ & 0.051 \\
\hline $\begin{array}{l}\text { Gl symptoms } \\
\text { GERD } \\
\text { Malabsorption } \\
\text { Anorectal incontinence }\end{array}$ & $\begin{array}{l}44(51.8 \% 6) \\
2(2.46) \\
1(1.266)\end{array}$ & $\begin{array}{l}90(62.5 \%) \\
5(3.5 \%) \\
4(2.86 \%)\end{array}$ & $\begin{array}{l}0.24 \\
20.99 \\
0.66\end{array}$ \\
\hline $\begin{array}{l}\text { Thyroid diseases } \\
\text { Bosedow }\end{array}$ & $1(1.256)$ & $\begin{array}{l}1(0.7 \%) \\
8(5.56)\end{array}$ & 20.99 \\
\hline $\begin{array}{l}\text { Hashimoto } \\
\text { SSC specific abs } \\
\text { Anti-Topolsomerase I } \\
\text { ACA }\end{array}$ & $\begin{array}{l}1(1.266) \\
68(2006)\end{array}$ & $\begin{array}{l}14(9.766) \\
98(68.18 \%)\end{array}$ & $\begin{array}{l}0.023 \\
0.012\end{array}$ \\
\hline $\begin{array}{l}\text { PBC specific abs } \\
\text { AMA } \\
\text { gp210 } \\
\text { sp100 }\end{array}$ & $\begin{array}{l}68(80 \% 5) \\
8(9.464) \\
6(7.166)\end{array}$ & : & \\
\hline $\begin{array}{l}\text { Therapy } \\
\text { Immunosuppressant therapy } \\
\text { Steroid therapy } \\
\text { Desoxicolic acid }\end{array}$ & $\begin{array}{l}18(21.266) \\
19(22.46) \\
58(68.266)\end{array}$ & $\begin{array}{l}43(29.996) \\
27(18.8 \%)\end{array}$ & $\begin{array}{l}\text { NS } \\
\text { NS }\end{array}$ \\
\hline Creatinine [median(10)] & $70(51.6-61.3)$ & $70(61.6-79.5)$ & 0.99 \\
\hline $\begin{array}{l}\text { Alanine transaminase [median(10)] } \\
\text { Aspartate transaminase [median(10)] }\end{array}$ & $\frac{34.5(26.59 .25)}{36(28.55)}$ & $\frac{20(1592.26)}{21(19-27)}$ & $\frac{0.002}{40.001}$ \\
\hline Alkaline phosphatase (AP) [median(IOa)] & $147(94-296)$ & $71(56 \cdot 90)$ & 60.001 \\
\hline VGT (median(1QQ)] & $143(59.5-253.5)$ & $18(11 \cdot 31.25)$ & 80.001 \\
\hline
\end{tabular}

Abstract THU0392 - Figure 1. Clinical features at baseline

Conclusions: PBC is more present in ACA positive IcSSc; SSc-PBC patients have a higher risk of polyautoimmunity. Of the most interest, SSc-PBC patients seem to have a milder SSc phenotype with less severe organ involvement and progression. Regarding PBC phenotype, only 4 patients presented portal hypertension and nobody was subjected to liver transplantation. At baseline, the SScPBC group had higher cholestatic liver enzymes and more than $60 \%$ were treated with deoxycholic acid. In the future, it will be useful to evaluate the PBC phenotype during the follow-up enrolling a greater number of patients.

Disclosure of Interest: None declared

DOI: 10.1136/annrheumdis-2018-eular.7076

\section{THU0393 THE PREDICTOR OF MALNUTRITION IN SYSTEMIC SCLEROSIS (PREMASS) SCORE: A VALIDATED COMBINED INDEX PREDICTIVE OF FUTURE WEIGHT LOSS IN SYSTEMIC SCLEROSIS}

${ }^{1}$ G. Bagnato, E. Pigatto ${ }^{2}$, A. Bitto ${ }^{3}$, N. Irrera ${ }^{3}$, C.G. Pizzino ${ }^{3}$, G. Abignano ${ }^{1}$, A. Ferrera ${ }^{4}$, D. Sciortino ${ }^{4}$, M. Hutichinson ${ }^{5}$, F. Squadrito ${ }^{3}$, M. Buch ${ }^{1}$, P. Emery ${ }^{1}$, E. Zanatta ${ }^{2}$, S. Gangemi ${ }^{6}$, W.N. Roberts ${ }^{7}$, A. Saitta ${ }^{8}$, F. Cozzi ${ }^{2}$, F. Del Galdo'. ${ }^{1}$ NIHR Leeds Biomedical Research Centre, Leeds Teaching Hospitals NHS Trust and Leeds Institute of Rheumatic and Musculoskeletal Medicine, University of Leeds, Leeds, UK; ${ }^{2}$ Rheumatology, Univeristy of Padova, Padova; ${ }^{3}$ Pharmacology;

${ }^{4}$ Rheumatology, University of Messina, Messina, Italy; ${ }^{5}$ Statistics, University of Leeds, Leeds, UK; ${ }^{6}$ Allergy and Clinical Immunology, University of Messina, Messina, Italy; ${ }^{7}$ Rheumatology, University of Lousiville, Louisville, USA; ${ }^{8}$ Internal Medicine, University of Messina, Messina, Italy

Background: Malnutrition and severe gastrointestinal dysfunction are the cause of mortality in $4 \%-15 \%$ of systemic sclerosis (SSc) patients whereas overall gastrointestinal involvement is observed in $75 \%-90 \%$ of cases. ${ }^{1}$ Hence, a reliable tool for stratification of risk for malnutrition would be of great value in the clinical management of SSc.

Objectives: Here we set out to identify a combined index predictive of significant weight loss at 12 months employing Malnutrition Universal Screening Tool (MUST) and serum adiponectin to leptin ratio (A/L) already used in other conditions.

Methods: This was an international, multicentre, longitudinal study employing 180 SSc patients in two independent cohorts: a study cohort (110 consecutive SSc patients) enrolled from University of Messina (60) and University of Padova, and a validation cohort (70) at the University of Leeds. Serum A/L ratio was measured by ELISA. MUST score, which includes BMI and weight loss reported by the patient in the last 3-6 months, was calculated as described: $0=$ no, $1=$ mild, $>2=$ moderate/severe risk of malnutrition. End point of the study was weight loss $>10 \%$ of baseline weight at 12 months.

Results: The two cohorts showed no significant differences in demographic and clinical features. Overall, median BMI decreased over time in both study and validation cohorts ( 23.5 vs 22.35 and 23.44 vs 22.49 , respectively; $p<0.0001)$. A/L 